\title{
The Times, They Are a Changin'
}

\author{
BY TOM GARRISON
}

A FAVORITE PROFESSOR of mine was fond of quoting the Spanish philosopher José Ortega y Gassett's definition of education: "the imaginative consideration of learning." This phrase resonates with me-deep inside most of us graying 60-something university professors resides the soul of a medieval scholar whose happiest workplace is a huge and poorly lit reading room in a quiet library. The prospect of being accidentally locked up overnight in a modern university library is not something many of us would regard with abject horror. We are good at focus and contemplation.

I mention this because of my peculiar teaching experiences through this last academic year. Something snapped. It's no surprise that the average student at my college has become steadily weaker in critical thinking skills. Seeing him or her grapple with a complex idea reminds me of watching a vast steam-powered Victorian machine slowly begin to move. (Coriolis effect applied to global wind patterns? More coal!) But this year the decline became a precipitous drop.

No one has ever improved upon the educational ideal of an inspiring professor sitting on one end of a log with a fascinated student on the other, but, lacking that, I say let the electrons flow!

I was not alone in noticing this change-all the instructors in the science teaching areas noticed the same thing.

This disconnect often became the topic of Friday informal department lunches. The consensus? Our students have largely lost the ability to "imaginatively contemplate." Like any other species, we profs must adapt or die.

Adapt doesn't mean giving in. Adapt means embracing what passes for contemplation in today's overly entertained student body and turning it to our advantage.

The next page shows what we've decided to do. (Wish us luck!) 
Administrators and students are greatly in favor of expanding online course offerings, but we propose to implement these kinds of classes with a crucial difference. None of our offerings would be offered exclusively online-students would spend at least half the course time in a classroom or laboratory in care of a certificated instructor (not a TA). The advantage is clear: Fewer fill-in-theblank exercises or cookbook lab sessions, the ability to answer questions in a group, and a chance to develop complex ideas in a lecture-discussion format.

Faculty teaching loads would reflect the extensive one-on-one time required to manage effective online instruction. Anyone with experience in online instruction knows his/her e-mail throughput rises exponentially while the class is in session, and reassigned time to cover this obligation would be a positive step.

Asynchronous delivery of course material would be common and efficient.

Chapter reviews could be recorded by the prof and distributed via downloadable podcasts (which is hugely appealing to our students). Any PowerPoint presentations used in class could be made available at the faculty member's Web site and downloaded for viewing on an iPod or computer. Voicemail? No problem.
Textbook publishers and instructors would work more closely together. The wealth of material being developed for texts in biology, geology, and marine science is extensive and usually of high quality, yet this resource is often overlooked by overworked faculty. Some publishers even provide PowerPoint files of each figure and table in a text.

The classroom experience must be modernized. Truly, the days of whiteboard and overhead projector are numbered (though I still miss chalk). When you look over a class in mid-lecture and see 150 students' faces bathed in the blue glow of their text-messaging mobile phones, you know you're doomed. Are you a grainy Edison image in a high-def world? Fix it! Ours is the most visually exciting of the sciences, and those photos and videos you've seen can be used to your great advantage as a lecturer. Yes, there are some rights issues to consider, but asking for permission to use video clips in the classroom is easy and nearly always productive.

Innovative ways to test mastery of concepts would be piloted. I have been adding visual questions to my written exams-pictures to identify, sort, and label. Our tests are of necessity of the ScanTron ${ }^{\circledR}$ type, but creative ways of combining images with a-b-c-d-e responses could be expanded.
Remember, we're people and so are students, no matter how disconnected they seem. Students respond to genuine interest in their academic struggles and triumphs. Come early to classes, talk to students, schedule many convenient office hours, feed them when you can!

Train your TAs in modern and traditional methods of instruction. They may be young with their mobile phones always at the ready, but that embryo medieval scholar lurks inside, waiting to be awakened.

No one has ever improved upon the educational ideal of an inspiring professor sitting on one end of a log with a fascinated student on the other, but, lacking that, I say let the electrons flow! Always remember that we elected to teach because we love the light The Aha Moment so effectively provides. Maybe "imaginative contemplation" can be packaged in ways we cannot yet imagine.

TOM GARRISON (tomgarrison@ sbcglobal.net) is an instructor at Orange Coast College, Costa Mesa, CA, USA. 